\title{
Anticipation in Huntington's disease is inherited through the male line but may originate in the female
}

\author{
R M RIDLEY*, C D FRITH*, T J CROW*, AND P M CONNEALLY $†$ \\ From * the Division of Psychiatry, Clinical Research Centre, Watford Road, Harrow, Middlesex HAl 3UJ; \\ and the Department of Medical Genetics, Indiana University, Indianapolis, Indiana 46223, USA.
}

SUMmaRY Data from the US National Huntington's Disease Roster have been analysed in terms of the difference in age of onset (AO) between affected parents and affected offspring, that is, in terms of 'anticipation'. While mean AO in offspring of affected mothers did not differ greatly from $\mathrm{AO}$ in their mothers, the distribution of $\mathrm{AO}$ in the offspring of affected fathers falls into two groups, the larger group showing an $\mathrm{AO}$ only slightly younger than their affected fathers and a small group whose AO was, on average, 24 years younger than their affected fathers. Analysis of the grandparental origin of the Huntington allele suggests that while propensity to anticipation is heritable for a number of generations through the male line, it originates at the time of differentiation of the germ line of a male who acquires the Huntington allele from his mother. It is suggested that major anticipation indicates an epigenetic change in methylation of the nucleic acid of the genome, which is imposed in the course of the 'genomic imprinting', that is, in the mechanism by which the parental origin of alleles is indicated.

Anticipation is the term used to describe the tendency for the age of onset (AO) of a dominantly inherited disorder to be younger in the proband than in the affected parent. We have analysed data from the US National Huntington's Disease Roster and found that, while anticipation in the maternal line is not greatly in excess of that predicted by normal variation and shows typical regression to the mean (such that offspring of mothers with young AO show negative anticipation), anticipation in the paternal line is notably skewed and positive across all AOs of the father. Although the propensity to anticipation is heritable through the male line, analysis of the grandparental origin of the gene suggests that it originates in transmission from a female. While anticipation which occurs when the gene has been inherited from a grandfather and father is uniformly distributed with respect to $\mathrm{AO}$ in the father, Huntington's disease (HD) which has been inherited from a grandmother and father shows positive rather than negative anticipation in the offspring of fathers with young $\mathrm{AO}$. Since no unusual change in $A O$ is seen when the gene is transmitted through a mother it appears that the propensity to anticipation is corrected by such transmission. We interpret these changes as showing that anticipation in HD is determined by an epigenetic change related to the

Received for publication 25 November 1987.

Revised version accepted for publication 1 February 1988. pattern of methylation of the nucleic acid sequence which is imposed in the course of 'genomic imprinting'. ${ }^{2}$ Specifically, an epigenetic change leading to major anticipation in affected offspring of affected males occurs during the process of differentiation of the germ cells (spermatogonia) of male embryos when the HD gene is inherited from a mother since this requires a methylation change. Such an epigenetic error can then be inherited indefinitely through the male line causing anticipation in offspring of either sex, but when the HD gene next passes through a female, genomic imprinting in her germ cells (oogonia) remethylates the HD gene and thereby corrects the error.

Anticipation is usually regarded as being the product of various possible ascertainment biases, although some ascertainment biases would work against the observation of anticipation (table 1). Most ascertainment biases could occur irrespective of whether the disease was inherited from the father or the mother, although the loss of affected pairs showing anticipation because the obligate carrier parent has died or lost contact with the proband before onset of illness in the parent may apply particularly to pairs where the disease is inherited from the father. Thus, one might expect that the phenomenon of anticipation, if it occurs as a consequence of ascertainment bias, would be equally apparent in father/offspring and mother/ 


\section{TABLE 1 Ascertainment bias producing anticipation.}

(1) At any one time, family data will include young people with a young $\mathrm{AO}$ but will exclude those of their sibs who will have an older $\mathrm{AO}$ but who are not yet affected.

(2) Onset of illness may be insidious and where disease has occurred recently in a parent the symptoms may be recognised at an earlier stage in the offspring. This source of bias is likely to be particularly important in families in which some members have become affected since the family has enrolled in the HD Roster.

(3) People with a very young AO have no children and therefore do not appear in the parental group.

(4) Parents with a young AO died when the proband was a child and cause and age of death in the parent is not known to the child.

(5) The older the $\mathrm{AO}$ in the offspring. the greater the probability that the offspring will be declared to be unaffected. This is particularly likely to occur when the offspring has an older AO than the parent.

(6) Where prodromal symptoms of the disease cause family breakdown the affected partner may lose contact with the rest of the family before diagnosis of the disease is established. Since young children usually remain with the mother, this may produce a particular loss of carly onset fathers. Similarly, where early symptoms lead to irresponsible behaviour at a young age, illegitimate births may occur. Detection of father/child pairs may be particularly difficult in these cases although loss of mother/child pairs through adoption may also occur. If $\mathrm{AO}$ showed simple regression to the mean, these two biases would result in a loss of parent/child pairs showing negative anticipation. If. however, as the evidence suggests. fathers with a young $\mathrm{AO}$ are particularly likely to produce children with an even younger AO, these effects may decrease the degree of observed anticipation in father/child pairs.

Ascertainment bias working against anticipation

(1) Parent/offspring pairs are not encountered when the parent would have had a very late $\mathrm{AO}$ but died of another illness first. This effect may occur more often in paternal lineage since, on average, males die earlier than females and are older than females at the time of conception of their children.

(2) Where contact between parent and offspring is lost because of illegitimacy or family breakdown which occurs for reasons unconnected with the onset of symptoms. late onset parents may be differentially lost from the sample. This is because contact between divorced or unmarried parents and their children is likely to become more sparse over time. Late onset fathers may be particularly prone to underascertainment by family breakdown.

(3) Parent/offspring pairs are difficult to detect when onset in the parent is so late as to occur after the time of diagnosis of the proband.

offspring pairs or, possibly, that anticipation should appear to be slightly greater when the disease is inherited from the mother. Major anticipation confined to one sex of parent would indicate some specific genetic or epigenetic event.

\section{Methods and results}

AGE OF ONSET IN PATERNALLY AND

MATERNALLY DERIVED CASES

A total of 3160 people with known AO of HD, for whom the sex of parent affected with HD was also known, was identified from the National Huntington's Disease Roster; 1508 cases had an affected father while 1652 had an affected mother. The mean AO of the paternally derived cases was 36.7 years while the mean $\mathrm{AO}$ of the maternally derived cases was 39.7 years. A comparable difference in $\mathrm{AO}$ by sex of parent has been reported previously for data from the National Huntington's Disease Roster ${ }^{34}$ and from elsewhere. ${ }^{56}$ The standard deviation of the paternally derived cases (12.08 years) was significantly greater than the standard deviation $\stackrel{\overparen{D}}{\rightarrow}$ of the maternally derived cases $(10 \cdot 79$ years $) \overrightarrow{\vec{F}}$ $(\mathrm{p}<0.001)$. There was no abnormal skew in the AO distribution in maternally derived cases (skew $=$ $+0.09, t=1.43$, NS). The AO in the paternally derived cases was not normally distributed (skew $=\frac{\overrightarrow{0}}{\mathrm{D}}$ $-0.23, t=3.69, \mathrm{p}<0.0001$ ).

The abnormality in the distribution of the pater- $\frac{0}{\infty}$ nally derived cases was the result of an excess of $\overrightarrow{0}$ early onset cases. Using maximum likelihood estimation procedures the best fit of the $\mathrm{AO} \vec{\omega}$ distribution was obtained from two normal distribu- $S$ tions with equal standard deviations. This gave a significantly better fit than one single normal distribution (maximum likelihood $\chi^{2}=29 \cdot 17$, df 2 , o $\mathrm{p}<0.0001)$. Parameter estimates suggested that $6 \%$ of the paternally derived cases fell into the early $\infty$ onset group with a mean AO of 16.2 years $(10.7$ o $\mathrm{SD})$. The remainder had a mean $\mathrm{AO}$ of 37.91 years $(10 \cdot 7 \mathrm{SD})$.

ANTICIPATION IN PATERNALLY AND

MATERNALLY DERIVED CASES

A total of 1693 cases of HD for which AO of proband and $\mathrm{AO}$ of affected parent were known was identified: 794 had an affected father and 899 had $\ddot{\bullet}$ an affected mother. Fig 1 shows anticipation fo 9 paternally and maternally derived cases. The mear. anticipation in the maternally derived cases was 1.35 years $(8.49 \mathrm{SD})(\mathrm{p}<0.05)$. There was only a small abnormal skew . (skew $=+0 \cdot 19, \quad t=2 \cdot 34, \mathrm{p}<0 \cdot 02)$ suggesting that serious ascertainment bias is not a $\mathbb{D}$ feature of the HD Roster data. The mean overall

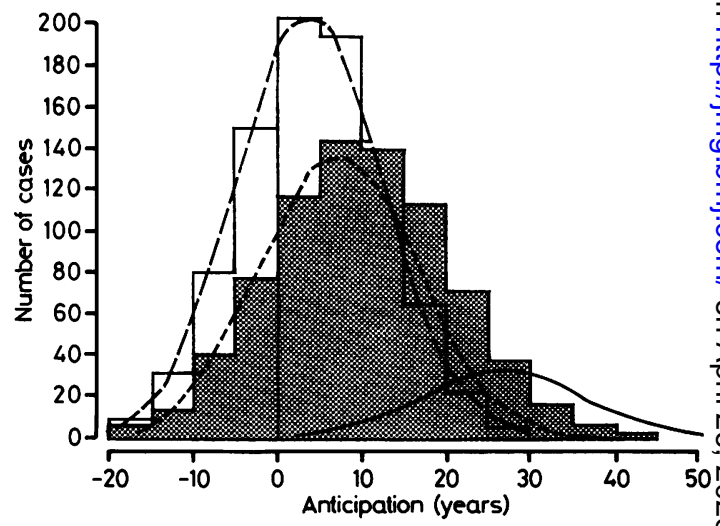

FIG 1 Best fit distributions of anticipation ( $A O$ parent-AO offspring). ---899 cases with an affected mother, - - - main distribution of cases with an affected father ( $n=643)$, _ subsidiary distribution of cases with an affected father $(n=151)$. Histograms of anticipation data from 794 cases with affected father (grey area) and 899 cases with an affected mother (white area). 
anticipation in the paternally derived cases was 6.73 years, although the distribution was not normal (skew $=+0.33, t=3.77, \mathrm{p}<0.001$ ). As in the case of the $\mathrm{AO}$ distribution, the anticipation distribution of the paternally derived cases was best described by two normal distributions, one showing only modest anticipation ( 4.6 years, $9.2 \mathrm{SD})$ and the other showing a major anticipation effect $(24 \cdot 3$ years, $9 \cdot 2$ SD). Fig 2 shows that cases with large anticipations show an excess of paternal origin.

The paternally derived group showing only modest (though significant, $\mathrm{p}<0.05$ ) anticipation did not differ significantly in anticipation from the whole maternally derived group. The difference in anticipation in the paternal line between the two subgroups which we have identified is large (19.7 years). The identification of affected men whose children may show large anticipation would have important prognostic value.

THE RELATIONSHIP OF ANTICIPATION IN OFFSPRING AND AO IN THE PARENT

There was a significant relationship between $\mathrm{AO}$ of parent and $\mathrm{AO}$ of offspring in both paternal and maternal lines. For the maternal line this relationship was only slightly curvilinear ( $\mathrm{F}$ ratio linear $v$ quadratic $=4.5, \mathrm{p}<0 \cdot 05, \mathrm{r}=0 \cdot 69)$ and showed typical regression to the mean. For the paternal line, however, the relationship was markedly curvilinear ( $\mathrm{F}$ ratio linear $v$ quadratic $=17.45, \mathrm{p}<0.0001$, $r=0 \cdot 62)$. These data can also be described as a slightly curvilinear relationship between anticipation in the offspring and $\mathrm{AO}$ of the mother $(\mathrm{r}=0 \cdot 38)$ and

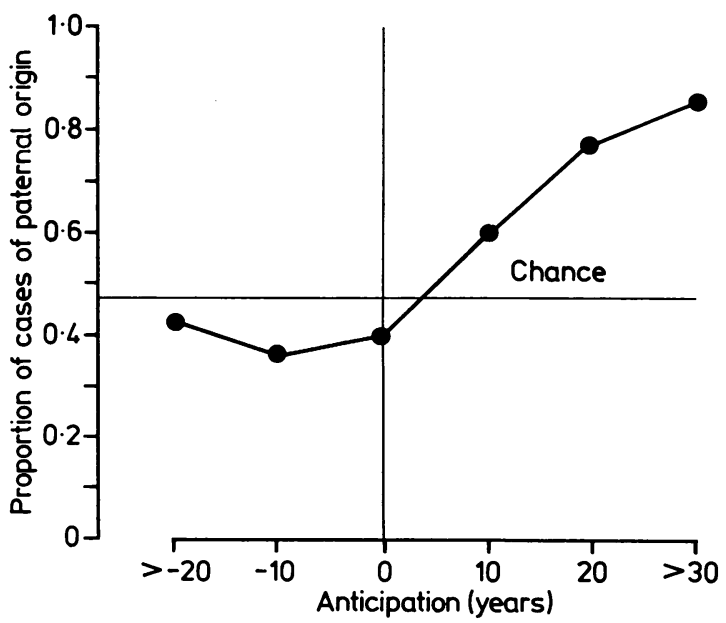

FIG 2 Graph showing proportion of cases of paternal origin for different degrees of anticipation in offspring. Total $n=899$ cases with affected mother, 794 cases with affected father. a markedly curvilinear relationship between anticipation in the offspring and $\mathrm{AO}$ of the father (multiple $r=0.34$ ) (fig 3a). Thus, as would be predicted from regression to the mean, anticipation is negative for the offspring of mothers with a younger than average $\mathrm{AO}(<35$ years) and positive for the offspring of mothers with an older than average $\mathrm{AO}$. For the offspring of affected fathers, however, mean anticipation was always positive and when $\mathrm{AO}$ in the father was $<30$ years, anticipation in the child increased as the $\mathrm{AO}$ of the father decreased. AO prognosis by sex of parent becomes widely divergent for offspring of parents with a young $\mathrm{AO}$.

RELATIONSHIP OF ANTICIPATION TO THE JUVENILE FORM OF HD

Juvenile onset HD is a variant of $H D$, some cases of which show special clinical and hereditary features. It might be expected that cases showing a large degree of anticipation would be likely to have a

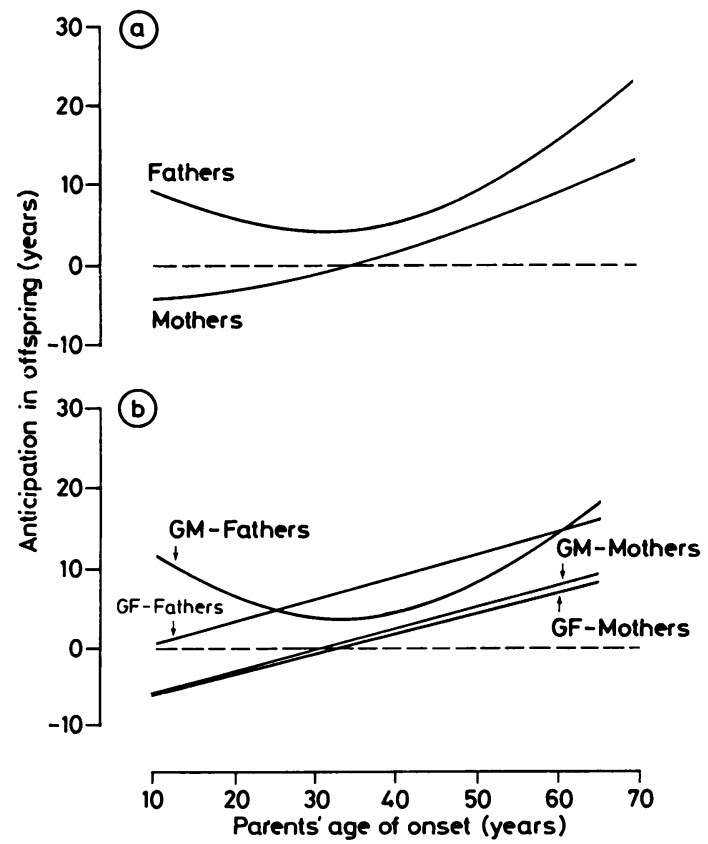

FIG 3 (a) Graphs of anticipation in offspring compared to $A O$ in parents for cases of maternal origin $(n=899)$ and paternal origin $(n=794)$. (b) Graphs of anticipation in offspring compared to $A O$ in parents for cases of different parental and grandparental origin.

$G M-$ Fathers $=$ affected grandmother and affected father $(n=271) . G F-$ Fathers $=$ affected grandfather and affected father $(n=274)$. GM-Mothers = affected grandmother and affected mother $(n=320)$. GF-Mothers=affected grandfather and affected mother $(n=314)$. 
juvenile $\mathrm{AO}$ (that is, less than 20 or 21 years). Some juvenile cases will, however, have a parent with a very young $\mathrm{AO}$ (and therefore not show much anticipation) while some cases with large anticipation will have a parent with a very old $\mathrm{AO}$ and will, themselves, have an AO near the mean. The relationship between anticipation and juvenile onset is therefore not clear.

We have defined juvenile onset cases as those with an $\mathrm{AO}<20$ years old and large anticipations as those $>15$ years (table 2 ). In the maternally derived cases $(n=899)$, there were nine juvenile onset cases which also showed large anticipations. The number expected by chance was two, so that the number observed is in excess of the expected $\left(\chi^{2}=22\right.$, $\mathrm{p}<0.001)$. This is probably because then anticipation is extremely large the $\mathrm{AO}$ in the offspring must necessarily be juvenile because the potential range of $\mathrm{AO}$ is greater than the range of age of reproductive competence. In the paternally derived cases $(n=794), 66$ juvenile onset cases associated with large anticipations were observed when only 22 were expected $\left(\chi^{2}=124, p \ll 0 \cdot 00001\right)$. In the maternally derived cases only $22 \%$ of those with large anticipations were of juvenile onset, while in the paternally derived cases, $46 \%$ of those with large anticipations were of juvenile onset. Juvenile cases arise particularly when large anticipation occurs in cases who have an affected father who himself has an early AO. There were 34 juvenile onset mothers and 24 juvenile onset fathers. Only three of the mothers $(9 \%)$ had children with an AO younger than their own, whereas 14 fathers $(58 \%)$ had children who showed anticipation. These results confirm that the fathers with the youngest $\mathrm{AO}$ have a strong tendency to produce offspring with an even younger $\mathrm{AO}$, most of whom will not reproduce.

It has been known for many years that the majority of cases of HD which have a juvenile AO have inherited the disease from their father. ${ }^{36-10}$ Went et al ${ }^{11}$ reported paternal descent in 12 of 13 infantile cases $(\mathrm{AO}<10$ years $)$ while Brackenridge ${ }^{12}$ found paternal descent in 49 of 60 cases with rigid? symptomatology and $\mathrm{AO}<12$ years. Our analysis shows that 142 of 183 cases with large anticipation? were of paternal origin even though only $41 \%$ ofe cases with large anticipation were of juvenile onset. $\frac{\bar{\sigma}}{\overline{\frac{5}{5}}}$ A total of 66 of 75 cases with large anticipation and juvenile onset were of paternal origin.

Juvenile onset is often associated with the rigid orv Westphal clinical variant of HD. ${ }^{12-15}$ When the rigidform is compared to the choreic form, two distinct AO distributions are seen. ${ }^{12}{ }^{13}$ More recently, van $\vec{\omega}$ Dijk $e t a l^{15}$ have argued that the particular features of juvenile $\mathrm{HD}$, especially the excess paterna $\bar{B}$ origin, in fact apply only to the rigid cases of juvenile HD. In these circumstances it may be better to regard rigid HD as the special entity of which juvenile onset is a typical but not obligatory featureo rather than vice versa. Paternal origin is a typical ${ }^{12}$ o but not obligatory ${ }^{16}$ feature of the rigid form of $\mathrm{HD}_{-}^{\supset}$ of any AO. This raises the possibility that the rigides form of HD is more closely associated with large anticipation than with juvenile onset.

EFFECT OF ANCESTRAL PHENOTYPE ON ANTICIPATION

The data presented have suggested that a feature $\delta_{0}^{0}$ one organism (the sex of the affected parent) influencing a feature of another organism (AOGंno offspring). The lack of any evidence that environment affects AO of HD argues against the effect of the sex of the parent on the child being environmen- $\frac{0}{D}$ tal and acting simply on phenotypic expression. $\cong$ Dawkins ${ }^{17}$ describes several instances in which the $\overrightarrow{\overline{0}}$ genotype of one organism affects the phenotype of 3 another organism without mediation through the genotype of the second organism (the 'extended? phenotype'). AO in HD may be another example of this phenomenon or it may indicate an effect of theo genotype of the parent on the genotype of the offspring which goes beyond simple inheritance. An: effect of parental phenotype on the genotype of theô offspring would be Lamarckian. Nevertheless, we

TABLE 2 Relationship between anticipation and juvenile onset in HD.

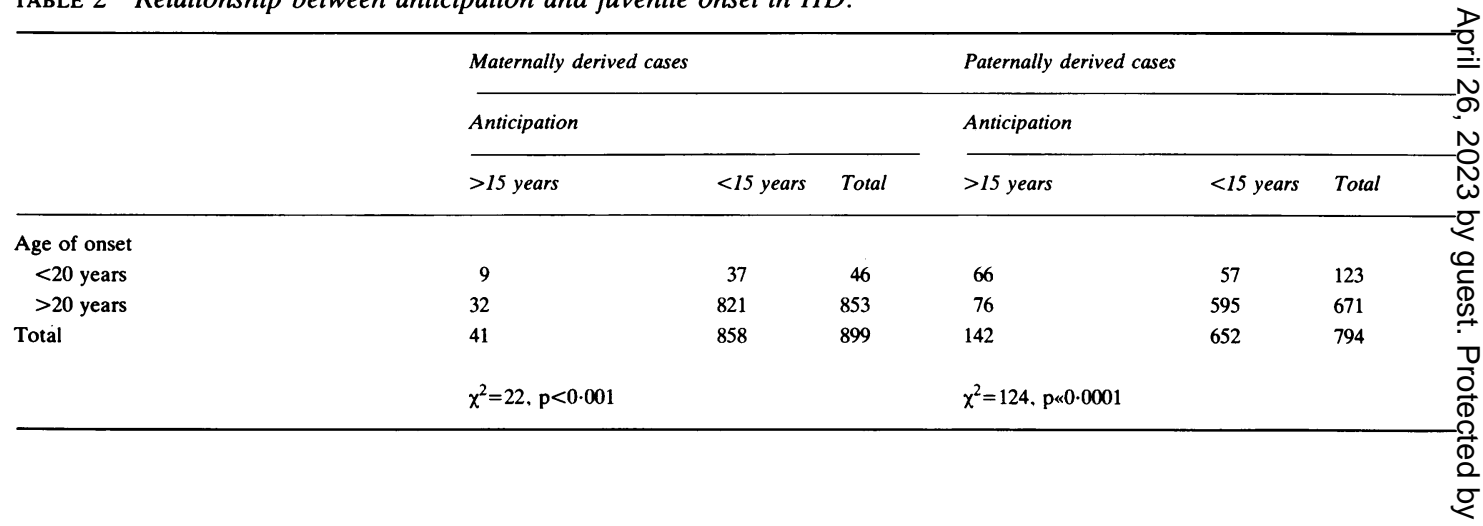


considered this possibility by examining the effect of the disease state (before or after the onset of symptoms) in the parent at the time of birth of the affected offspring and by examining the effect of season of birth, since many physiological parameters in the parent could show seasonal variation. In order to examine disease state independently of the correlation in AO between parent and child, the sample was divided into six AO of parent groups, each of 10 years' extent, and the AO in the offspring was compared in those parents who were already symptomatic with those parents who were not symptomatic in each $\mathrm{AO}$ group. No effect of disease state in the parent was found. Similarly, although the number of affected people born each month varied across the calendar, there was no significant difference in the seasonal variation between those people who showed major anticipation ( $>15$ years) and those who did not. These findings suggest that the source of the effect of the sex of the parent on AO in offspring should be sought in the germ line rather than in the soma of the parent.

Since the effect on the AO of the offspring could occur, not at the time of conception of the child but at the time of the creation of the germ line in the parent, we also looked at the effect of the disease state in the affected grandparent at the time of birth of the affected parent, and the season of birth of the affected parent on anticipation in the offspring, but found no difference in these variables between offspring with large anticipation and those without.

THE ORIGIN OF THE EVENT LEADING TO LARGE ANTICIPATION

Our results indicate that in HD of maternal origin, large anticipations do not occur with a frequency much greater than that predicted by normal variation, but that in a subgroup of cases of HD of paternal origin, some special reason for an excess of large anticipations may be sought, either in an affected subject, or in the affected father, or in a more distant ancestor.

There were 1179 probands for whom the sex and
AO of the affected parent and the sex of the affected grandparent could be ascertained (table 3). As expected, mean $\mathrm{AO}$ in paternally derived cases was younger than maternally derived cases in this sample (paternal line 32.6 years, maternal line 36.9 years, $\mathrm{p}<0 \cdot 01)$. There was also a significant interaction between sex of parent and sex of grandparent on $A O$ in the proband $(F(1,1175)=6 \cdot 7, p<0.01)$. The sex of the affected grandparent had no effect on the AO of probands who inherited the disease through their mother. For paternal inheritance the sex of the grandparent did affect the AO of the proband, the AO in probands with affected grandfathers and fathers being 4.3 years younger than those with affected grandmothers and fathers. Figure $3 \mathrm{~b}$ shows the relationship between anticipation in the offspring and $\mathrm{AO}$ in the parent divided up according to the sex of the affected parent and grandparent. These graphs show normal linear regression in all groups except those who inherit the disease from their grandmother and father. The grandfather-father regression is parallel to the two grandparent-mother lines suggesting that the normal mechanisms leading to regression (polygenic modification, ${ }^{18}$ multiple ageing genes ${ }^{19}$ ) operate independently of the extra propensity to anticipation in the offspring of some affected grandfathers and fathers. This could occur if the extra propensity to large anticipation were inherited at the HD locus for a number of generations via the paternal line.

Since the sex of the affected grandparent had no effect on the AO of the offspring of affected mothers (who show very little mean anticipation anyway), it would seem that passage of the HD gene through an oogonium eliminated the propensity to large anticipation. This beneficial effect is the same as the 'maternal protective factor' identified by previous workers. ${ }^{3} 520$

In the grandmother-father line there was a curvilinear relationship between the $A O$ of the father and the probability that his offspring will show a major anticipation. That this particular relationship is only seen in those fathers who inherit the disease from their mother suggests that the

TABLE 3 Mean (SD) age of onset and anticipation in proband depending on sex of parent and grandparent.

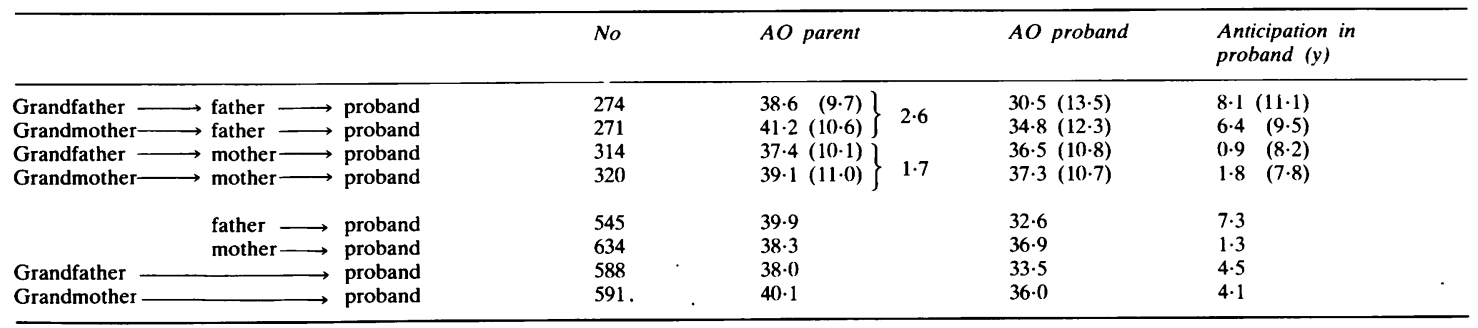


mechanism leading to major anticipation begins before the time of conception of the father and depends on whether the HD allele in the father has been donated by an egg or a sperm. Nevertheless, it should be stressed that the majority (41 of 61 ) of juvenile onset, large anticipation children who inherited the disease from their father were also known to have had an affected grandfather. This could occur if the propensity to anticipation were inherited indefinitely through the male line until the AO became too young for reproduction to occur.

METHYLATION OF THE HD ALLELE AS A

MECHANISM OF ANTICIPATION

The mechanism of 'genomic imprinting' by which genes are labelled as being of maternal or paternal origin involves the degree of methylation of chromosomal segments. ${ }^{12}$ Genes in an oogonium thus have a different methylation state from genes in a spermatogonium. At conception these maternal/paternal origin methylation states are retained in all the cells of the embryo except those which differentiate to become the germ line. Cells in the germ line are remethylated according to the sex of the embryo, that is, genes in the germ line of a male embryo (in spermatogonia) are methylated as being of paternal origin while genes in the germ line of a female embryo (in oogonia) are methylated to indicate maternal origin. Our proposition is that major anticipation occurs in offspring (male or female) whose $\mathrm{HD}$ allele is methylated as being of paternal origin but where this methylation is defective. A defective methylation of 'paternal origin' may be inherited indefinitely through the male line causing a propensity to anticipation in any subsequent offspring (male or female). When the incorrectly methylated $\mathrm{HD}$ allele is passed via an $\mathrm{X}$ sperm to a female embryo it will retain the incorrect methylation state in the somatic cells of that embryo (producing anticipation in later life), but the HD allele in the germ line of that female will be remethylated as being 'of maternal origin'. If the methylation state 'of maternal origin' is less likely to be defective (perhaps because 'paternal origin' comprises less methylation than 'maternal origin') then this remethylation to the 'maternal origin' will correspond to the 'maternal protective factor' 520 and will account for the lack of an excess of major anticipations in the offspring of affected mothers. Since any change of state is more likely to generate errors than a continuity of state, it follows that the production of defective methylation states 'of paternal origin' are most likely to occur when a 'maternal origin' HD allele is remethylated as a 'paternal origin' HD allele in the germ line of a male embryo conceived by a mother who, herself, carries the HD allele.

\section{Discussion}

The results of this analysis are in agreement with $\overrightarrow{\vec{D}}$ previous analyses which found that the AO of HD is, on average, younger in those who inherit the 흐 disease from their father rather than their mother. ${ }^{3-6} \frac{\overline{\bar{c}}}{\overline{6}}$ Our analysis suggests, however, that the mean AO $\mathbb{\otimes}$ in the offspring of most affected fathers is similar to

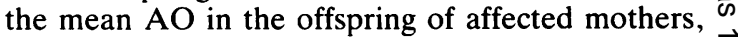
but that a major decrease in AO occurs in the $\vec{O}$ offspring of a small group (6\%) of affected fathers. $\overrightarrow{\vec{H}}$ In the offspring of this subgroup, AO is decreased $\omega_{\sigma}$ by approximately 20 years. Folstein $e t a^{21}$ described two large pedigrees differing in major symptomatology. In one pedigree (in which the major symptoms î at onset were psychiatric), there was little difference 6 in $\mathrm{AO}$ between the offspring of affected fathers and on $_{\infty}$ affected mothers. In the other pedigree (in which 0 the major symptoms at onset were motor), the $\mathrm{S}$ offspring of affected fathers had a mean AO which $\vec{C}$ was 16 years younger than the offspring of affected $\mathbb{D}$ mothers. Thus, of the two pedigrees described by $\frac{\vec{\Phi}}{\vec{D}}$ Folstein et al, ${ }^{21}$ one would appear to come from the $\frac{\mathbb{}}{3}$ subset with earlier AO in the offspring of affected fathers, while the other pedigree would appear not to belong to this group. These pedigrees werg $\stackrel{\oplus}{\infty}$ analysed using the G8 probe and the locus of te HD allele did not differ between the pedigrees in relation to the G8 probe.

Since reproductive success is related to $\mathrm{AO}$ in $\mathrm{HD},{ }^{3}$ it might be supposed that if $\mathrm{AO}$ in the offspring of affected fathers is gradually and gener- $\frac{\mathbb{Q}}{\mathbb{Q}}$ ally reduced, the $\mathrm{AO}$ in the male line of descent $\overrightarrow{\vec{A}}$ would eventually become so young as to be incom- $\frac{0}{3}$ patible with reproduction and HD would not be $\frac{3}{5}$ inherited indefinitely through the male line. OurF analysis suggests, however, that in the majority of pedigrees HD can be inherited indefinitely through the male line with little decrease in AO. In the remaining pedigrees, some branches must ultimately 3 . die out. These branches could begin with an affected mother whose sons' children show anticipation and $\frac{1}{2}$ end with a juvenile onset case born to a father with $a_{0}$ young AO. A limited number of affected males (but 3 not females) may occur between the original $\frac{7}{0}$ affected mother and the last, non-reproductive juvenile onset case. Nevertheless, the loss of repro- $\mathbb{N}$ ductive fitness in the male line should not be underestimated. Overall, affected males do not have sufficient offspring to sustain the disease in the population, although this may be compensated for by the excess reproductive fitness of affected women. $22-25$

The AO of symptoms of a genetic disorder may reflect changes in gene expression over time or as a consequence of senescence (for example, oncogene- 
sis) or the cumulative phenotypic effect of a permanent genetic state (for example, phenylketonurea). The existence in the Venezuelan pedigrees of substantial numbers of HD homozygotes, who are normal before the onset of symptoms and indistinguishable in $\mathrm{AO}$ and clinical course from HD heterozygotes ${ }^{26}{ }^{27}$ suggests that either the normal (wild type) allele at the HD locus has no phenotypic effects or that the HD allele acts as a fairly normal functional gene before the onset of clinical symptoms, with only minor, non-deleterious phenotypic differences ${ }^{28}$ from the normal allele. The latter alternative is more probable since the normal allele at the HD locus, and hence the locus itself, would not be conserved in the absence of an adaptive phenotypic effect. This implies that the onset of symptoms indicates a change in expression of the HD allele.

Changes in the degree of methylation of DNA can control gene activation and inactivation, age dependent changes in gene expression, and can occur as part of the ageing process. ${ }^{29}$ All of these processes could be involved in the control of $\mathrm{AO}$ and clinical variant (rigid/choreic) in HD. In particular, if the onset of symptoms in HD is determined by an age dependent demethylation (and hence altered expression) of the HD gene, then the degree of methylation of the HD allele in the somatic cells present from early embryogenesis may have profound effects on the age at which a particular threshold of demethylation is reached. If the number of methylation sites is limited, then a change in the number of methylated sites on the HD allele in the somatic cells from one generation to the next may cause the sort of large anticipatory events in a small subset of cases which we have demonstrated. Heritable epigenetic states such as methylation may also contribute to the variable expression and reduced penetrance seen in other genetic disorders.

We would like to thank Dr L Farrer for helpful discussions and encouragement.

\section{References}

${ }^{1}$ Reik W, Collick A, Norris ML, Barton SC, Surani MA Genomic imprinting determines methylation of parental alleles in transgenic mice. Nature 1987;328:248-51.

2 Sapienza C, Peterson AC, Rossant J, Balling R. Degree of methylation of transgenes is independent of gamete of origin. Nature 1987;328:251-4.

${ }^{3}$ Boehnke M, Conneally PM, Lange K. Two models for a maternal factor in the inheritance of Huntington's disease. Am J Hum Genet 1983;35:845-60.

4 Conneally PM. Huntington's disease: genetics and epidemiology. Am J Hum Genet 1984;36:506-26.

5 Myers RH, Cupples LA, Schoenfeld M, et al. Maternal factors in onset of Huntington's disease. Am J Hum Genet 1985;37: 511-23.
${ }^{6}$ Newcombe RG, Walker DA, Harper PS. Factors influencing age of onset and duration of survival in Huntington's chorea. Ann Hum Genet 1981;45:387-96.

7 Merritt AD, Conneally PM, Rahman NF, Drew AL. Juvenile Huntington's chorea. Excerpta Medica Int Congr Ser 1969;175: 645-73.

${ }^{8}$ Myrianthopoulos NC. Huntington's chorea: an appraisal of the genetic problem. In: Barbeau A, Brunette JR, eds. Progress in neurogenetics. Vol 1. Amsterdam: Excerpta Medica Foundation, 1969:509-16.

9 Myers RH, Madden JJ, Teague JL, Falek A. Factors related to onset age of Huntington's disease. Am J Hum Genet 1982;34: 481-8.

${ }^{10}$ Hayden MR, MacGregor JM, Saffer DS, Beighton PH. The high frequency of juvenile Huntington's chorea in South Africa. J Med Genet 1982;19:94-7.

1 Went LN, Vegter-van der Vlis M, Brign GW. Parental transmission in Huntington's disease. Lancet 1984;i:1100-2.

12 Brackenridge CJ. The relation of sex of affected parent to the age of onset of Huntington's disease. J Med Genet 1973;10: 333-6.

13 Bittenbender JB, Quadfasel FA. Rigid and akinetic forms of Huntington's disease. Arch Neurol 1962;7:275-88.

14 Brackenridge CJ. The relation of the sex of choreic and rigid subjects to the age of onset of Huntington's disease. Clin Genet 1974;5:248-53.

15 van Dijk JG, van der Velde EA, Roos RAC, Brugn GW. Juvenile Huntington's disease. Hum Genet 1986;73:235-9.

16 Bird MT, Paulson GW. The rigid form of Huntington's chorea. Neurology (Minneap) 1971;21:271-6.

17 Dawkins R. The extended phenotype: gene as the unit of selection. London: W H Freeman, 1982.

18 Haldane JBS. The relative importance of principal and modifying genes in determining some human diseases. $J$ Genet 1941;41:149-57.

${ }^{19}$ Farrer LA, Conneally PM, Yu PI. The natural history of Huntington's disease: possible role of aging genes. Am J Med Genet 1984;18:115-23.

${ }^{20}$ Farrer LA, Conneally PM. A genetic model for age of onset in Huntington's disease. Am J Hum Genet 1985;37:350-7.

21 Folstein SE, Phillips JA, Myers DA, et al. Huntington's disease: two families with differing clinical features show linkage to the G8 probe. Science 1985;229:776-9.

22 Reed TE, Neel JV. Huntington's chorea in Michigan 2. Selection and mutation. Am J Hum Genet 1959;11:107-36.

23 Jones MB. Fertility and age of onset in Huntington's chorea. In: Barbeau A, Chase TN, Paulson GW, eds. Advances in neurology. Vol 1. New York: Raven Press, 1973:171-7.

24 Marx RN. Huntington's chorea in Minnesota. Adv Neurol $1973 ; 1: 237-43$

25 Wallace DC, Parker N. Huntington's chorea in Queensland: the most recent story. Adv Neurol 1973;1:223-36.

26 Young AB, Shoulson I, Penny JB, et al. Huntington's disease in Venezuela: neurologic features and functional decline. Neurology (Minneap) 1986;36:244-9.

27 Wexler NS, Young AB, Tanzi RE, et al. Homozygotes for Huntington's disease. Nature 1987;326:194-7.

${ }^{28}$ Farrer LA, Yu PI. Anthropometric discrimination among affected, at-risk, and not-at-risk individuals in families with Huntington's disease. Am J Med Genet 1985;21:307-16.

${ }^{29}$ Holliday R. The significance of DNA methylation in cellular aging. In: Woodhead AD, Blackett AD, Hollaender A, eds. Molecularbiology of aging. New York: Plenum Press, 1985:269-83.

Correspondence and requests for reprints to Dr R M Ridley, Division of Psychiatry, Clinical Research Centre, Northwick Park Hospital, Watford Road, Harrow, Middlesex HA1 3UJ.

.

